\title{
Improved Modeling for Pressure Drop in Microtubes
}

\author{
Kaveh Hariri Aslia*, Faig Bakhman Ogli Naghiyev, Soltan Ali Ogli Aliyev and \\ Akbar Khodaparast Haghid \\ aDepartment of Mathematics and Mechanics, National Academy of Science of Azerbaijan "AMEA" \\ Baku, Azerbaijan. Postal Address: No.1045, Alley Azerbany 2, Farhang Ring, Rast, Iran \\ bDepartment of Mathematics and Mechanics, National Academy of Science of Azerbaijan "AMEA" \\ - Baku, Azerbaijan \\ 'Azerbaijan State Oil Academy, Baku, Azerbaijan \\ dUniversity of Guilan, Rasht, Iran
}

(received September 9, 2009; revised August 10, 2011; accepted September 6, 2011)

\begin{abstract}
The study was carried to predict the pressure drop in the microtubes by applying a finite volume solver. The full Navier-Stoke's approach is examined for this kind of narrow tubes for the pressure drop evaluations. The complete form of the energy equation with the dissipation terms is also linked to the momentum equations. The computed pressure drop show good agreements with the experimental data. The effects of flow rate and channel geometry on the pressure drop of the system are also predicted.
\end{abstract}

Keywords: microtubes, pressure drop, finite volume method, aspect ratio

\section{Introduction}

New methods of liquid cooling are introduced by developing the micro fabrication technology. The combine attributes of very high surface area to volume ratio; large convective heat transfer coefficient, small mass and volume, and small coolant inventory make micro-channel heat sinks suitable for cooling of devices such as high performance micro-processors, laser diode, radars, and high energy laser mirrors. To design effective microtubes heat sink, fundamental under-standing of the characteristics of heat transfer and fluid flow in micro-channels are necessary. At the early stages, the designs and relations of macroscale fluid flow and heat transfer were employed. However many experimental observations in micro-channels deviate significantly from those in macroscale channels. These disagreements were first observed by Tuckerman and Pease (1981). They demonstrated that micro rectangular passages have a higher heat transfer coefficient in laminar regimes in comparison with turbulent flow through macroscale channels; therefore they are capable of dissipating significant high heat fluxes (Hariri et al., 2010a). Since the regime of the flow has a noticeable influence on studying determination of heat dissipation rate, several researches have been conducted in this field. Wu and Little (1983) measured the heat transfer characteristics for gas flows in miniature channels with inner diameter ranging from 134 to $164 \mathrm{~mm}$. The tests involved both

\footnotetext{
*Author for correspondence; E-mail: Hariri_k@yahoo.com
}

laminar and turbulent flow regimes. Their results showed that the turbulent convection occurs at Reynolds number of approximately 1000.They also found that the convective heat transfer characteristics depart from the predictions of the established empirical correlations for the macroscale tubes. They attributed these deviations to the large asymmetric relative roughness of the microchannel walls. Harms et al. (1997) tested a $2.5 \mathrm{~cm}$ long, $2.5 \mathrm{~cm}$ wide silicon heat sink having $251 \mu \mathrm{m}$ wide and $1030 \mu \mathrm{m}$ deep micro-channels. A relatively low Reynolds number of 1500 marked transition from laminar to turbulent flow which was attributed to a sharp inlet, relatively long entrance region and channel surface roughness. They concluded that the classical relation for Nusselt number was fairly accurate for modeling micro-channel flows. Fedorov and Viskanta (2000) reported that the thermal resistance decreases with Reynolds number and reaches an asymptote at high Reynolds numbers. Qu et al. (2000) investigated heat transfer and flow characteristics in trapezoidal silicon microtubes. In comparison, the measured friction factors were found to be higher than the numerical predictions. The difference was attributed to the wall roughness. Based on a roughness-viscosity model, they explained that the numerically predicted Nusselt numbers are smaller than the experimentally determined ones. Choi et al. (1991) measured the convective heat transfer coefficients for flow of nitrogen gas in micro tubes for both laminar and turbulent regimes. They found that the measured Nusselt number in laminar flow exhibits 
a Reynolds number dependence in contrast with the conventional prediction for the fully developed laminar flow, in which Nusselt number is constant. Adam et al. (1998) conducted single-phase flow studies in microtubes using water as the working fluid. Two diameters of the circular microtubes, namely $0.76 \mathrm{~mm}$ and $1.09 \mathrm{~mm}$, were used in the investigation. It was found that the Nusselt numbers are larger than those encountered in microtubes. Peng and Peterson (1996) investigated water flows in rectangular microtubes with hydraulic diameters ranging from 0.133 to $0.336 \mathrm{~mm}$. In laminar flows, it was found that the heat transfer depends on the aspect ratio and the ratio of the hydraulic diameter to the center-to-center distance of the micro-channel. Mala and Dale (1997) considered the electrical body forces resulting from the double layer field in the equations of motion. These effects are negligible in the macroscale as the dimensions of the electric double layer, EDL, is very small with respect to tube dimensions. They solved the Poisson-Bolzmann equation for the steady state flow. It was found that without the double layer a higher heat transfer rate is obtained. They proposed to consider the effects of the EDL on liquid flows and heat transfer in microtubes to prevent the over estimation of the heat transfer capacity of the system. Xu et al. (2002) investigated the effects of viscous dissipation on the micro scale dimensions. They used a 2D microtube and considered the viscous dissipation term in energy equation. The results show that this term plays a significant role in temperature, pressure and velocity distributions. Therefore, the relationships between the friction factor and the Reynolds number change when the hydraulic diameter of the microtube is very small. The viscous dissipation effects are brought about by rises in the velocity gradient as hydraulic diameter reduces for a constant Reynolds number. In this article, a numerical study is conducted based on the experimental results of Tuckerman (1984) and Hariri et al. (2010b).

\section{Materials and Methods}

At this work the fluid flow and pressure drop inside the tubes are considered. The numerical results based on finite volume method are then compared with the available experimental data. The effects of liquid velocity through channels and their effects on pressure drop along microchannels are investigated. Finally, the effects of aspect ratio on pressure drop in microtubes are predicted. The experimental and numerical research on micro-channel fluid flow was presented in the paper. Diameters of the microtubes were $0.1,0.3$ and $0.5(\mathrm{~mm})$ and the flow regime was laminar with Re-number range up to 800 . The working fluid was distilled water and the tube material was stainless steel. The experimental setup was designed in such a way that the investigation of the average friction factor and developing heat transfer was possible. Due to the large scattering in the reported experimental results, the scope of this research was to make the accurate measurements and to compare the experimental fluid flow characteristics with numerical and theoretical results for the conventional tubes. The characteristics of the model are depicted in Figs. 1-2. The width and thickness of micro-channels are $\mathrm{W} 1$ and $\mathrm{H} 1$ respectively. The thickness of the silicon substrate is $\mathrm{H} 2-\mathrm{H} 1$; and the total length of the micro-channels is $\mathrm{L}$. The heat supplies by a $1 \mathrm{~cm} \times 1 \mathrm{~cm}$ heat source located at the entrance of the channels and are centered across the whole channel heat sink. A uniform heat flux of $q$ is provided to heat the micro-channels. The heat is removed by flowing water through channels. The inlet temperature of the cooling water is $22^{\circ} \mathrm{C}$. The analysis is performed for five different cases. The dimensions related to each case are given in Table 1. By these dimensions; there will be 150 microchannels for cases 0 and 1 and 200 micro-channels for cases 2,3 , and 4 . The case 2 was considered as the base geometry. The water velocity changed from $50 \mathrm{~cm} / \mathrm{s}$ to $400 \mathrm{~cm} / \mathrm{s}$. The Tuckerman's geometries were solved by the unique Reynolds of 150 . To prevent the various boundary condition effects, the computational domain is taken at the center of the heat sink to have the quoted uniform heat flux. This is because there is very little spreading of heat towards the heat sinks. There is also some geometrical symmetry which simplifies the computation. So, only a semi-channel and semi-silicon substrate will be considered and the results will be the same for the other half. The whole substrate is made of silicon with thermal conductivity $(k)$ of $148 \mathrm{~W} / \mathrm{m}$. K. At the top of the channel $y=\mathrm{H}_{2}$, there is a Pyrex plate to make an adiabatic condition (its thermal conductivity is two orders lower than silicon). There are two different boundary conditions at the bottom. For $\mathrm{z}<\mathrm{L}_{\mathrm{h}}$ a uniform heat flux of $q$ is imposed over the heat sink and the rest is assumed to be adiabatic. Water flows through the channel from the entrance in $z$ direction. The transverse velocities of the inlet are assumed to be zero. The axial velocity is considered to be evenly distributed through the whole channel. The velocities at the top and bottom of tubes are zero (Hariri et al., 2010c).

Formulation. For the fluid flow and pressure drop in a unit cell there are assumed: steady fluid flow; 
incompressible fluid; laminar flow; constant solid and fluid properties. In the last assumption the solid and liquid properties are assumed to be constant because of the small variations within the temperature range tested.
Based on the above assumptions, the governing differential equations (1-16) used to describe the fluid flow in a unit cell are expressed as follows (Hariri et al., 2010c):

$$
\begin{aligned}
& \left(\mathrm{P}_{1} / \gamma\right)+\mathrm{Z}_{1}\left(\mathrm{~V}_{1}{ }^{2} / 2 \mathrm{~g}\right)+\mathrm{h}_{\mathrm{p}}=\left(\mathrm{P}_{2} / \gamma\right)+\mathrm{Z}_{2}+\left(\mathrm{v}_{2}{ }^{2} / 2 \mathrm{~g}\right)+\mathrm{h}_{\mathrm{L}}, \\
& (\mathrm{g} / \mathrm{a})(\mathrm{dH} / \mathrm{dt})+\mathrm{dv} / \mathrm{dt}+(\mathrm{fv}|\mathrm{v}| 2 \mathrm{~d})=0 \Rightarrow(\mathrm{ds} / \mathrm{dt})=\mathrm{c}^{+}, \\
& -(\mathrm{g} / \mathrm{a})(\mathrm{dH} / \mathrm{dt})+\mathrm{dv} / \mathrm{dt}+(\mathrm{fv}|\mathrm{v}| 2 \mathrm{~d})=0 \Rightarrow(\mathrm{ds} / \mathrm{dt})=\mathrm{c}^{-}, \\
& (\mathrm{dp} / \mathrm{dt})=(\partial \mathrm{p} / \partial \mathrm{t})+(\partial \mathrm{p} / \partial \mathrm{s})(\mathrm{ds} / \mathrm{dt}), \\
& (\mathrm{dv} / \mathrm{dt})=(\partial \mathrm{v} / \partial \mathrm{t})+(\partial \mathrm{v} / \partial \mathrm{s})(\mathrm{ds} / \mathrm{dt}), \\
& (\partial \mathrm{v} / \partial \mathrm{t})+(1 / \rho)(\partial \mathrm{p} / \partial \mathrm{s})+\mathrm{g}(\mathrm{dz} / \mathrm{ds})+(\mathrm{f} / 2 \mathrm{D}) \mathrm{v}|\mathrm{v}|=0, \\
& \mathrm{C}^{2}(\partial \mathrm{v} / \partial \mathrm{s})+(1 / \mathrm{P})(\partial \mathrm{P} / \partial \mathrm{t})=0,
\end{aligned}
$$

(Euler Eq.),

By linear combination of Euler and continuity equations:

$$
\begin{aligned}
& \lambda[(\partial \mathrm{v} / \partial \mathrm{t})+(1 / \rho)(\partial \mathrm{p} / \partial \mathrm{s})+\mathrm{g}(\mathrm{dz} / \mathrm{ds})+(\mathrm{f} / 2 \mathrm{D}) \mathrm{v}|\mathrm{v}|]+\mathrm{C}^{2}(\partial \mathrm{v} / \partial \mathrm{s})+(1 / \mathrm{p})(\partial \mathrm{p} / \partial \mathrm{t})=0, \\
& \lambda=^{+} \mathrm{c} \& \lambda=^{-} \mathrm{c} \\
& (\mathrm{dv} / \mathrm{dt})+(1 / \mathrm{cp})(\mathrm{dp} / \mathrm{ds})+\mathrm{g}(\mathrm{dz} / \mathrm{ds})+(\mathrm{f} / 2 \mathrm{D}) \mathrm{v}|\mathrm{v}|=0, \\
& (\mathrm{dv} / \mathrm{dt})-(1 / \mathrm{cp})(\partial \mathrm{p} / \partial \mathrm{s})+\mathrm{g}(\mathrm{dz} / \mathrm{ds})+(\mathrm{f} / 2 \mathrm{D}) \mathrm{v}|\mathrm{v}|=0,
\end{aligned}
$$

(continuity Eq.)

$$
(\partial w / \partial z)=0
$$

(Momentum Eq.)

$$
\begin{aligned}
\rho\left(\partial\left(w_{i} w_{j}\right) / \partial z_{j}\right)= & -\left(\partial p / \partial z_{i}\right)+\mu\left(\partial / \partial z_{j}\right)\left(\left(\partial w_{i} / \partial z_{j}\right)+\left(\partial w_{j} / \partial z_{i}\right)\right) \\
& (-2 / 3) \mu\left(\partial / \partial z_{i}\right)\left(\partial w_{k} / \partial z_{k}\right)
\end{aligned}
$$

(Energy Eq.)

$$
\rho c_{p}\left(\partial w_{j} T / \partial z_{J}\right)=K\left(\partial^{2} T / \partial x_{j}{ }_{j}\right)+\mu \Phi
$$

Where

$$
\begin{aligned}
\Phi= & 2\left[(\partial \mathrm{u} / \partial \mathrm{x})^{2}+(\partial \mathrm{v} / \partial \mathrm{y})^{2}+(\partial \mathrm{w} / \partial \mathrm{z})^{2}\right]+((\partial \mathrm{u} / \partial \mathrm{y})+(\partial \mathrm{v} / \partial \mathrm{x}))^{2} \\
& +((\partial \mathrm{u} / \partial \mathrm{z})+(\partial \mathrm{w} / \partial \mathrm{x}))^{2}+((\partial \mathrm{v} / \partial \mathrm{z})+(\partial \mathrm{w} / \partial \mathrm{y}))^{2}
\end{aligned}
$$



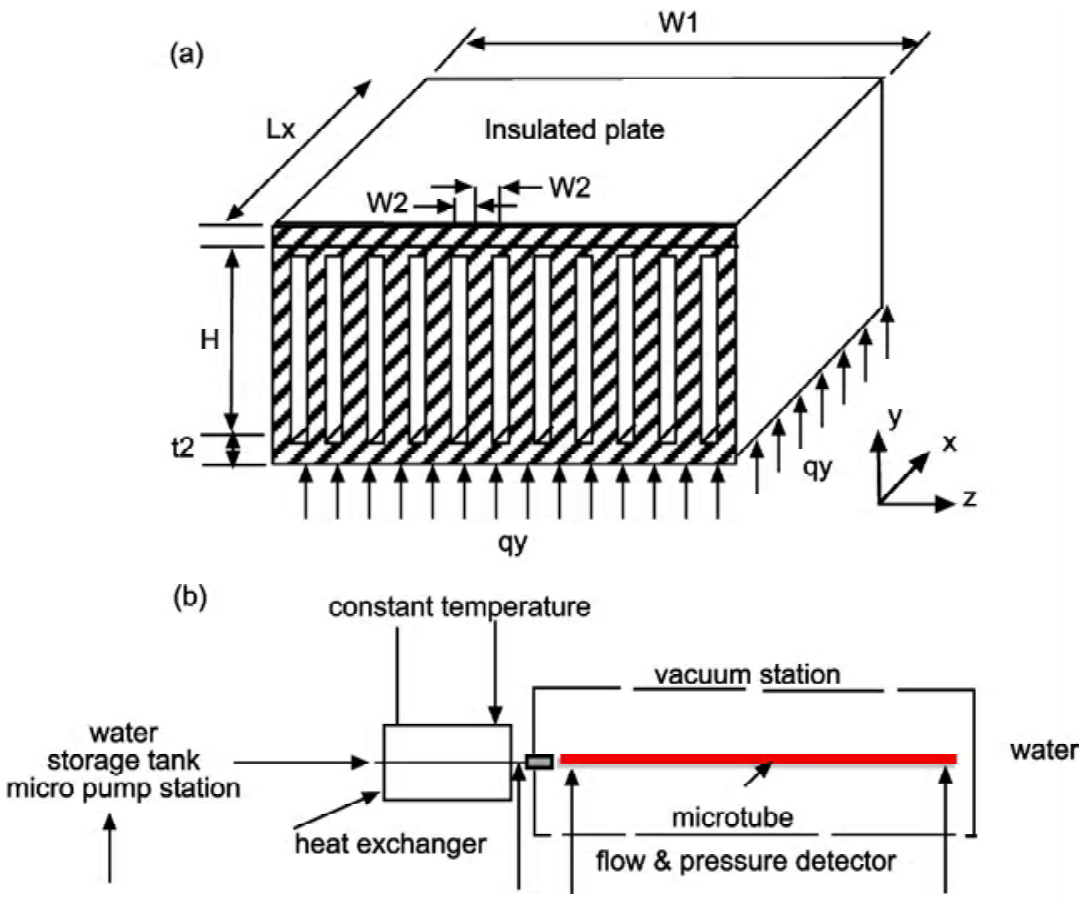

Fig. 1. Experimental model: (a) Micro-channel diagram (b) Instrumentation.

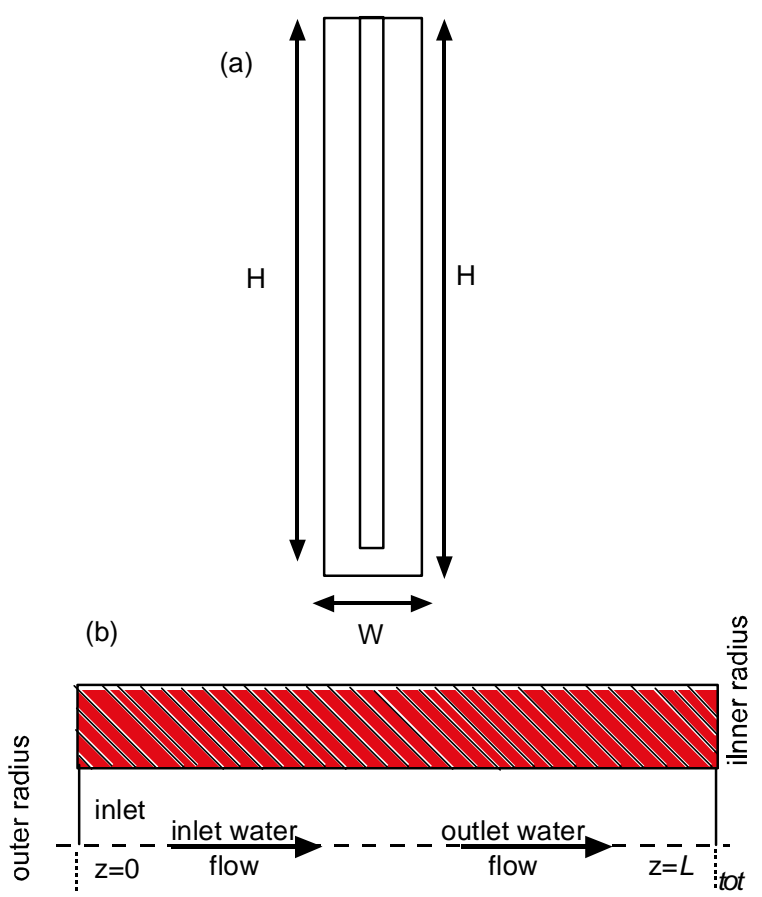

Fig. 2. Test tube presentation: (a) Geometry of micro-channel (b) Test tube.

\section{Results and Discussion}

The Finite Volume Method (FVM) is used to solve the continuity, momentum, and energy equations. A very brief description of the method used is given here. In this method the domain is divided into a number of control volumes such that there is one control volume surrounding each grid point. The grid point is located in the center of a control volume. The governing equations are integrated over the individual control volumes to construct algebraic equations for the discrete dependent variables such as velocities, pressure. The discretization equation then expresses the conservation principle for a finite control volume just as the partial differential equation expresses it for an infinitesimal control volume. In the present study, a solution is deemed converged when the mass imbalance in the continuity equation is less than $10^{-6}$.As the flow characteristics are of the great importance in design of micro-channel heat sinks, the results are concentrated in these fields. For solving the equations several grid structures were used. The grid density of $120 \times 40 \times 20$ in $z, y$, and $x$ directions is considered to be appropriate. The Reynolds number is calculated as:

$$
\operatorname{Re} \equiv\left(\rho w_{\text {ave. }} D_{k}\right) / \mu
$$

where:

$$
\mathrm{D}_{\mathrm{h}} \equiv(4 \mathrm{~A} / \mathrm{P})=\left(2 \mathrm{H}_{1} \mathrm{~W}_{1} /\left(\mathrm{H}_{1}+\mathrm{W}_{1}\right)\right)
$$

First, pressure drops based on the numerical results are demonstrated (Hariri et al., 2010c). Then the numerical 


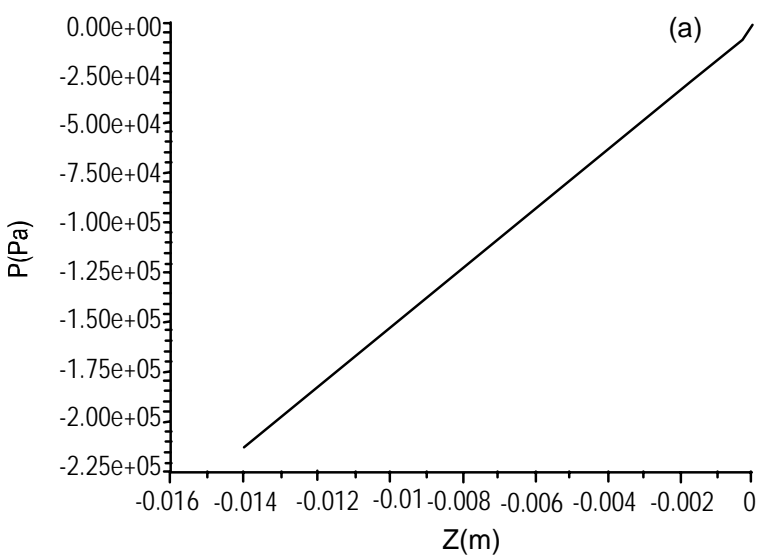

(b)

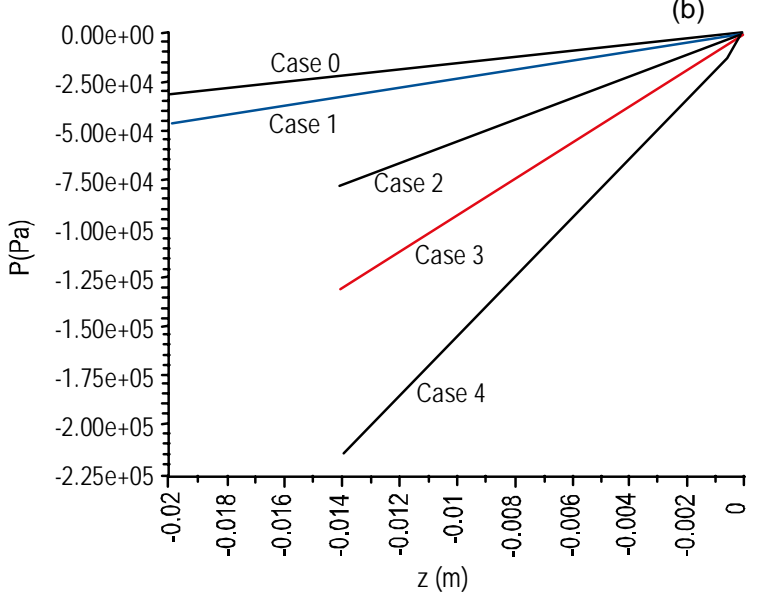

Fig. 3. Pressure drop, (a) case 4, (b) all cases

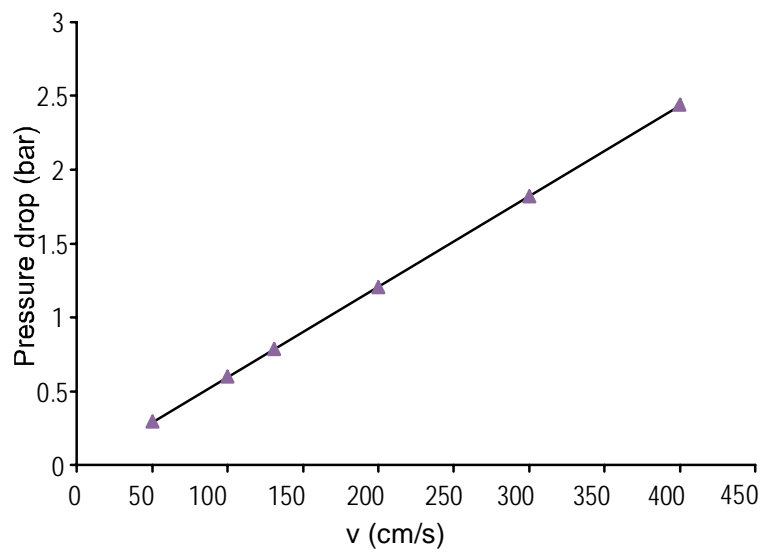

Fig. 4. Pressure drop for different velocities.

results are compared with Tuckerman's experiments data.

Pressure drop. Pressure drop is linear along the channel. Fig. 3 (a) shows the pressure drop for Case 4 . The pressure drop increases by increasing the inlet velocity. The slope of the pressure line in the entrance of the channel is maximum. This is due to the entry region

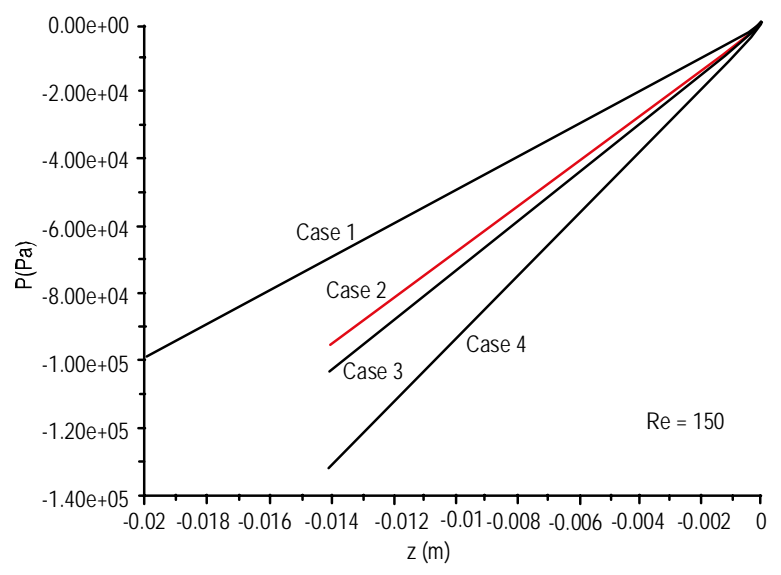

Fig. 5. Pressure drop for each geometry in constant Reynolds of 150.

Table 1. Four different cases of micro-channels

\begin{tabular}{llllll}
\hline \hline Case & 0 & 1 & 2 & 3 & 4 \\
\hline $\mathrm{L}(\mathrm{cm})$ & 2 & 2 & 1.4 & 1.4 & 1.4 \\
$\mathrm{~W}^{1}(\mu \mathrm{m})$ & 64 & 64 & 56 & 55 & 50 \\
$\mathrm{~W}^{2}(\mu \mathrm{m})$ & 36 & 36 & 44 & 45 & 50 \\
$\mathrm{H}^{1}(\mu \mathrm{m})$ & 280 & 280 & 320 & 287 & 302 \\
$\mathrm{H}^{2}(\mu \mathrm{m})$ & 489 & 489 & 533 & 430 & 458 \\
$\mathrm{Q}\left(\mathrm{cm}^{3} / \mathrm{s}\right)$ & 1.277 & 1.86 & 4.7 & 6.5 & 8.6 \\
$\mathrm{q}\left(\mathrm{W} / \mathrm{cm}^{2}\right)$ & 34.6 & 34.6 & 181 & 277 & 790 \\
Number of & & & & & \\
channels & 150 & 150 & 200 & 200 & 200 \\
\hline \hline
\end{tabular}

Table 2. Pressure drop in 5 Cases

\begin{tabular}{ll}
\hline \hline Case & Pressure drop (bar) \\
\hline 0 & 0.322 \\
1 & 0.469 \\
2 & 0.784 \\
3 & 1.302 \\
4 & 2.137 \\
\hline
\end{tabular}

effects. The velocity field will be fully developed after a small distance $f$ rom the entrance. So the assumption of fully developed flow is acceptable. Fig. 3(b) shows the pressure drop for all 5 cases. These amounts are tabulated in Table 2. The effects of velocity on the pressure drop in microtubes are displayed in Fig. 4. The pressure drop is a linear function of velocity. The amounts of temperature rise and pressure drop are given in Table 3. Aspect ratio is an important factor in microtube design (Hariri et al., 2010a). In this section 
Table 3. Temperature rise and pressure drop

\begin{tabular}{llll}
\hline \hline $\begin{array}{l}\text { Velocity } \\
(\mathrm{cm} / \mathrm{s})\end{array}$ & Re & $\begin{array}{l}\text { Temp. } \\
\text { rise }\left({ }^{\circ} \mathrm{C}\right)\end{array}$ & $\begin{array}{l}\text { Pressure } \\
\text { drop (bar) }\end{array}$ \\
\hline 50 & 47 & 40.6 & 0.298 \\
100 & 95 & 25.4 & 0.598 \\
131 & 124 & 21.9 & 0.784 \\
200 & 190 & 18.0 & 1.206 \\
300 & 285 & 15.5 & 1.817 \\
400 & 380 & 14.2 & 2.439 \\
\hline \hline
\end{tabular}

the inlet heat flux of $181 \mathrm{~W} / \mathrm{cm}^{2}$ imposed over the heat sinks and the hydraulic diameter changes between 85.8 and 104.2. This case has the minimum pressure drop too (Fig. 5). The pressure drop of these two cases has a noticeable difference.

\section{Conclusion}

At this work, a full three-dimensional simulation for fluid flow for single micro-channel heat sink was developed. Comparison with analytical and experimental research findings of the other experts shows validity of results. The pressure drop increases with increase in aspect ratio. The numerical results of pressure drop were shown and the results had good consistency with experimental data. The results also gave the required assurance of using the full Navier-Stokes approach for the microtubes with the hydraulic diameters of about $0.1 \mathrm{~mm}$. However, for lower hydraulic diameters in the range of molecular mean free paths length scales, some modifications must be prepared for the flow equations. The effects of water velocity and aspect ratio on the pressure drop of these tubes are also predicted. The results show that an optimum design of microtubes with respect to pressure drop must be considered. Thus, it may be concluded that the present methodology is able to predict the total pressure drop of any microchannel heat sinks satisfactorily.

\section{Nomenclature}

$\mathrm{A}=$ flow area; $\mathrm{cp}=$ Specific heat; $\mathrm{Dh}=$ hydraulic diameter; EDL = Layer; H1 = channel height; H2 = total height; $\mathrm{k}=$ thermal conductivity; $\mathrm{L}=$ heat sink length; Lh = heated length; $\mathrm{p}=$ pressure; $\mathrm{P}=$ wetted perimeter; $\mathrm{q}=$ heat flux; $\mathrm{Q}=$ total volumetric flow rate; $\mathrm{R}=$ thermal resistance; $\mathrm{Re}=$ Reynolds number; $\mathrm{t}=$ Time; $\lambda 0$ = Unit of length; $\mathrm{V}=$ Velocity; $\mathrm{S}=$ Length;
$\mathrm{D}=$ Diameter of each pipe; $\mathrm{R}=$ Pipe radius; $\gamma=$ Specific weight; $v=$ Fluid dynamic viscosity; $h p=$ Head gain from a pump; $\mathrm{hL}=$ Combined head loss; $\mathrm{C}=$ Velocity of surge wave; $\mathrm{p} / \gamma=$ Pressure head; $\mathrm{z}=$ Elevation head; $\mathrm{V} 2 / 2 \mathrm{~g}=$ Velocity head; $\gamma=$ specific weight; $\mathrm{Z}=$ elevation; $\mathrm{Hp}=$ head at pipeline points- intersection points of characteristic lines; $\mathrm{Vp}=$ velocity at pipeline points- intersection points of characteristic lines; g = Gravitational acceleration constant; Vri = velocity at right hand side of intersection points of characteristic lines; Hri = head at right hand side of intersection points of characteristic lines; Vle = velocity at left hand side of intersection points of characteristic lines; Hle = head at left hand side of intersection points of characteristic lines; $\mathrm{C}^{-}=$characteristic lines with negative slope; $\mathrm{C}^{+}=$characteristic lines with positive slope; Min. = Minimum; Max. = Maximum; $\mathrm{w}=$ velocity ( $\mathrm{z}$ direction); $\mathrm{W} 1$ = channel width; W2 = substrate width:

\section{Greek symbol;}

$\Phi=$ viscous dissipation terms in energy equation; $\mu=$ viscosity; $\rho=$ density:

\section{Subscript;}

Ave. $=$ average; in = inlet; $\mathrm{T}=$ temperature.

\section{References}

Adams, T.M., Abdel-Khalik, S.I., Jeter, S.M., Qureshi, Z. H.1998. An experimental investigation of singlephase forced convection in micro-channels. International Journal of Heat Mass Transfer, 41: 851-857.

Choi, S.B., Barren, R.R., Warrington, R.O.1991. Fluid Flow and Heat Transfer in Microtubes, ASME DSC 40, pp.89-93.

Fedorov,A.G., Viskanta, R. 2000. Three-dimensional conjugate heat transfer into microchannel heat sink for electronic packaging. International Journal of Heat Mass Transfer, 43: 399-415.

Harms, T.M., Kazmierczak, M.J., Cerner, F.M., Holke, A., Henderson, H.T., Pilchowski, J., Little Baker, K. 1997. Experimental investigation of heat transfer and pressure drop through deep micro-channels in a (100) silicon substrate, In: Proceedings of the ASME. Heat Transfer Division, HTD 351, pp.347-357.

Hariri, A.K., Nagiyev, F.B., Haghi, A.K. 2010a. Physical modeling of fluid movement in pipelines. In: Nanomaterials Yearbook-2009, From Nanostructures, Nanomaterials and Nanotechnologies to Nanoindustry, pp.197-214, $1^{\text {st }}$ edition, Nova Science 
Publications, New York, USA.

Hariri, A.K., Nagiyev, F.B., Haghi, A.K. 2010b. A numerical study on fluid dynamics. In: Material Science Synthesis, Properties, Applicators. pp. 101$110,1^{\text {st }}$ edition, Nova Science Publications, New York, USA.

Hariri, A.K., Nagiyev, F.B., Haghi, A.K. 2010c. Some aspects of physical and numerical modeling of water hammer in pipelines. Nonlinear Dynamics, 60: $677-70$.

Hariri, A.K., Nagiyev, F.B., Haghi, A.K.2009. Interpenetration of Two Fluids at Parallel Between Plates and Turbulent Moving in Pipe. In: Computational Methods in Applied Science and Engineering, pp.115-128, $1^{\text {st }}$ edition, Nova Science publisher, New York, USA.

Mala, Li, G.D., Dale, J.D.1997.Heat transfer and fluid flow in microchannels. Journal of Heat Transfer, 40: 3079-3088.

Peng, X.F., Peterson, G.P.1996. Convective heat transfer and flow friction for water flow in microchannel structure. International Journal of Heat and Mass Transfer, 36: 2599-2608.

Qu, W., Mala, G.M., Li, D.2000. Heat transfer for water flow in trapezoidal silicon microchannels. International Journal of Heat and Mass Transfer, 43: 3925-3936.

Tuckerman, D.B., Pease, R.F.W. 1981. High performance heat sinking for VLSI. IEEE Electron Device Letter, DEL-2: 126-129.

Tuckerman, D.B. 1984. Heat transfer micro-structures for integrated circuits, Ph.D. Thesis, Stanford University, California, USA.

Wu, P.Y., Little. W.A.1983. Measurement of friction factor for flow of gases in very fine channels used for micro miniature, Joule Thompson refrigerators. Cryogenics, 273-277.

Xu, B., Ooi, K.T., Mavriplis, C., Zaghloul, M. E. 2002. Viscous dissipation effects for liquid flow in microchannels. Microsystems, pp.100-103. 